\title{
Nota Sobre el Punto de Vista Narrativo en Hijo de Hombre de Roa Bastos
}

Yo era muy chico entonces. Mi testimonio no sirve más que a medias. (p. 13).

La primera impresión que da una lectura de Hijo de hambre es que los nueve capítulos son la narración de Miguel Vera, el ex militar que muere al final del noveno capítulo y cuyos escritos son descubiertos y dados a luz por su amiga Rosa Monzón con la esperanza de que algún fin sirvan "en estos momentos en que el país vuelve a estar al borde de la guerra civil."' La mayoria si no la totalidad de los que han estudiado la novela han llegado fácilmente a la opinión de que Vera es el único narrador y que, dada la carta de Monzón al final del libro, debemos comprender la historia relatada hasta este punto como una combinación de recuerdos, evocaciones, y diarios de Vera. Así, Seymour Menton, en un reciente análisis, nota cierta variación en la forma presentacional del militar, pero igual no ve inconveniente alguno en aceptar a Vera como el único narrador. ${ }^{2}$

Yo también había mantenido esta posición de la exclusividad narrativa de Vera - con la obvia excepción de la carta de Monzón, la cual

1 Augusto Roa Bastos, Hijo de hombre (Buenos Aires: Losada, 1960), p. 228. Todas las citas de la novela son de esta edición.

2 "Realismo mágico y dualidad en Hijo de hombre", Revista lberoamericana, 33 (1967), 55-70. Ver. p. 67: "Los nueve capítulos se narran alternativamente entre la tercera persona y la primera (Miguel Vera). Vera mismo explica esta técnica y nota sus efectos fantásticos". La implicación es que Vera narra también los capítulos de tercera persona para crear un efecto fantástico. Hugo Rodríguez Alcalá, en "Hijo de hombre, de Roa Bastos y la intrahistoria del Paraguay", Cuadernos Americanos, 121 (1963), 221-34, también nos da a entender que Vera es el único "relator" (p. 224). 
nos suministra ciertos datos ya evidentes sobre la personalidad y el "romanticismo" endeble de aquél, en mi estudio sobre la obra de Roa Bastos. $^{3}$ Sin embargo, una nueva lectura de la novela me ha convencido de que esa caracterización de su estructura es poco acertada y que es preciso admitir que sólo una mitad de los capítulos son narrados por Vera y que en la otra mitad vienen narrados por otro.

La razón por la cual se había llegado a la conclusión de que Vera es el narrador se debe a que él mismo se coloca dentro de la acción novelesca de varios capítulos, y así viene a ser no sólo espectador-narrador, sino también un partícipe directo en los acontecimientos que está detallando. Efectivamente, en cierto momento se transforma en catalizador cuando traiciona en una borrachera a Jara y su grupo revolucionario (Caps. 5-7), cuando se encuentra cercado sin agua en el Chaco y despachan a Jara y su camión de agua para salvar a él y a sus hombres (Cap. 8), cuando provoca el entusiasmo vacio del pueblo a la vuelta a Itapé de uno de los ex combatientes, espiritualmente destrozado y quemado por dentro, entusiasmo que llega a simbolizar la hipocresía de la guerra oficial (Cap. 9).

Sin embargo y a pesar de que Vera participa directamente, "observándose a sí mismo" como partícipe en algunos de los capítulos, nosotros ahora queremos insistir en que sólo los capítulos impares son narrados directamente por Vera. Y, excepto una referencia a Vera y su traición por los personajes principales del sexto capítulo, Vera no participa en los acontecimientos del segundo, cuarto, sexto y octavo capítulos. ${ }^{4}$ En el primer capítulo, que establece el contexto tanto histórico como "espiritual" de la novela, 5 Vera nos cuenta lo que recuerda de Macario, de Gaspar Mora, y del Cristo que talló Mora. El Cristo, ahora colgado de una cruz y situado en un lugar sagrado sobre un collado de las afueras de Itapé, es el símbolo recurrente del libro, como dice Vera en sus ten. tativas de interpretar a Mora y al pueblo paraguayo, o del hombre crucificado que tienen que vengar o del Cristo que tienen que castigar por

${ }^{3}$ David William Foster, The Myth of Paraguay in the Fiction of Augusto Roa Bastos (Chapel Hill: University of North Carolina Press, 1969), p. 55.

${ }^{4}$ En el sexto capítulo leemos el siguiente trozo de diálogo: "- Teniente Vera!...-barbotó el oficial-. ¿Me ha oído?-lo removió [a Vera] con la punta de la bota" (p. 115). ¿Es Vera, desdoblándose para tratar con fría objetividad la desgracia de su traición, o es la voz de otro narrador? No podemos saber con seguridad, pero este trozo igual representa un ejemplo de una voz narrativa que no es indudablemente la de Vera.

5 Sobre el rol del primer capítulo, ver el trabajo de Rodríguez Alcalá citado en la segunda nota. En mi estudio mencionado en la tercera nota, se encuentra una discusión detallada de lo que sólo podemos mencionar sumariamente aquí. 
no haber cumplido con su promesa de aliviar el sufrimientu del hombre. ${ }^{6}$ En términos de la totalidad de la novela, este capítulo establece el tono unificador de una historia de dimensión mítica del pueblo paraguayo. En términos de Vera, es su mejor vuelo sentimental de recreación de un momento decisivo, en sus ojos, del pueblo que apenas penetra en sus esfuerzos de comprensión.

En el tercer capítulo, Vera nos relata su viaje de Itapé a la escuela militar de Asunción. Viaja con una mucama de la casa y su criatura enferma, a quien durante la noche Vera le roba la leche de los pechos de su madre, inciđente que Vera narra sin evaluación para subrayarnos las primeras manifestaciones de sus graves debilidades de carácter. Para que haya ilación entre los capítulos, uno de los incidentes del tercer capítulo tiene que ver con el médico ruso, Dubrovsky, cuya historia se ha desarrollado ya en el segundo capítulo. En el quinto capítulo, que es el centro geométrico de la novela y el primer encuentro entre las dos figuras antitéticas, Vera y Jara —uno el Judas y otro el Cristo- Vera recuerda su caminata con Jara al viejo vagón de tren donde los esperan los revolucionarios que quieren pedir a Vera que les dé instrucciones militares. Casi la totalidad del capítulo se dedica a la caminata. Vera recuerda para nosotros que se acordaba de los acontecimientos anteriores del pueblo, como el bombardeo de los revolucionarios de la generación del padre de Jara, los mismos padres, ya legendarios, de Jara, el médico ruso, y las leproserías que construyó y que todavía se divisan a alguna distancia del pueblo. Vera camina detrás de Jara y las espaldas cicatrizadas de éste le despiertan la memoria.

En el séptimo capítulo, Vera, por medio de entradas de un diario, recrea su estancia en el destino de Peña Hermosa, donde lo llevan después de su traición a Jara y donde queda hasta el estallido de la Guerra del Chaco cuando lo nombran oficial y va al frente para ser luego cercado sin agua. El uso del diario tiene la ventaja de crear la ilusión de una presentación objetiva de la personalidad interior de Vera, pues las entradas escritas cada tantos días constituyen una trayectoria que el diarista no habrá notado en su ensimisamiento pero que nosotros percibimos inmediatamente. Es una trayectoria hacia el delirio y la alucinación, delirio y alucinación que otra vez sirven para revelarnos la inestabilidad

${ }^{6}$ Ver p. 13 de la novela. La cuestión del Cristo es examinada en mi trabajo, "The Figure of Christ Crucified as a Narrative Symbol in Roa Bastos' Hijo de hombre", Books Abroad, 37 (1963), 16-20. Sin conocer mi trabajo, Urte Lenherdt repite en un análisis más detallado de la novela las mismas observaciones, "Ensayo de interpretación de Hijo de hombre, a través de su simbolismo cristiano y social", Revista Iberoamericana, 34 (1968), 67-82. 
del carácter del narrador. Aunque el lector descuidado va a aceptar esta ilusión del diario como confiable, hay al final algo que destruye en gran parte la posibilidad de que lo aceptemos como una composición hecha día por día. Me refiero a la entrada final donde Vera describe en detalle, cuando él y sus tropas ya no pueden más en su locura frenética producida por la falta de agua, su mismo desmayo en el momento en que llega el camión de agua de Jara. La sección viene encabezada con una fecha y tiene toda la apariencia de un entrada de diario. Pero las últimas palabras describen algo que Vera no pudo haber escrito al mismo tiempo que le pasaba:

\section{9 de septiembre}

[...] El camión ha aparecido por fin en la boca de la picada. [...] En medio de una nube de polvo, con las ruedas en llamas, el camión ha avanzado zigzagueando por el cañadón. [...] $\mathrm{Ha}$ seguido avanzando con el tanque bamboleante y las ruedas en llamas, erizado de vívidos penachos de agua, hasta embicar contra un árbol. Esta ahí..., está llamándome... (p. 165)

Se supone que Vera se desmaya en ese momento. Así, aunque las otras entradas sean "legítimas" y por eso confiables, esta última tiene que haber sido escrita y agregada al diario mucho después del acontecimiento descrito cuando Vera ya se sintiera capaz de recordar con detalle -0 de imaginar con detalle- ese último día de su actuación militar.

El noveno capítulo, como ya hemos indicado, refiere la vuelta de un ex combatiente y el choque que él y sus subsiguientes actos, junto con los de otros ex combatientes, producen en la imaginación fértil de Vera. Aunque sus palabras finales expresen un profundo sentimiento de Roa Bastos, también son buenos indicios de su tendencia a romantizar, a sentimentalizar, a convertir todo en emocionalismo. Ver, por ejemplo, su evocación de lo que ha de suceder en el futuro (pp. 222-23). Será la verdad, pero es la alta emoción desenfrenada con la cual está evocada, lo que nos atrae la atención como revelante de Vera.

En contraste, los capítulos pares no sólo no incluyen a Vera como partícipe, sino también son momentos en lugares que a Vera le habría sido difícil si no imposible presenciar. Se puede decir que el hecho de que Vera no aparezca en los capítulos pares como partícipe no tiene importancia. O Vera se habrá vuelto más controlado, optando por sofrenar el egoísmo que se destaca en los capítulos impares, o es una cuestión de Vera llenando con los capítulos pares las lagunas de su memoria a 
base de investigaciones posteriores. Lo cierto es que los acontecimientos de los capítulos pares, en contraste con los impares, relatan sucesos que Vera no pudo haber observado directamente. Como se sabe, la acción narrativa del segundo capítulo, dedicado al médico ruso, transcurre cuando Vera está en Asunción en la escuela militar. El cuarto capítulo, que relata la horrorosa experiencia de los padres de Jara en los yerbales del Alto Paraná, se refiere a una época antes del nacimiento de Vera o muy poco después. Como es de la misma edad de Jara, quien nace un poco antes del legendario éxodo bíblico de los padres de la inmensa hacienda de la empresa extranjera, Vera sólo podría narrar a base de lo que los otros le dijeron. $\mathrm{Y}$ con esto abordamos un problema más significativo. No es sólo una cuestión de que Vera no pudiera haber participado en los acontecimientos del cuarto capítulo - sus investigaciones e indagaciones posteriores le habrían provisto de tantos datos como recuerdos borrosos sobre los asuntos. Pero, más importante es el hecho de que, aún con sus investigaciones, es poco probable que Vera hubiera llegado a poder reconstruir con tanto detalle la vida de Natí y Casiano en TukurúPukú. ¿De dónde habrá sacado los datoś? Seguramente no de los padres, quienes ya habían muerto cuando Vera está en Sapukai en el quinto capítulo, recién expulsado de la escuela militar. Y seguramente no de Cristóbal Jara, quien comunica más con los gestos que con las palabras. Aunque lo de los padres había llegado a ser un mito de Sapukai, los mitos del pueblo son a base de conflictos y valores y no registran los detalles necesarios para que Vera nos recree la vida del yerbal. Tampoco el sexto capítulo puede ser de Vera. Cuando traiciona a Jara, le mandan aI destino de Peña Hermosa, donde está internado hasta la Guerra del Chaco. Otra vez, a base de indagaciones después de la Guerra pudo haber completado la laguna, que en este caso tiene que ver con la suerte de Jara después de la traición, único sobreviviente de los revolucionarios que extermina con eficiencia el gobierno. Pero cuando uno recuerda que Vera muere como a un año después de la Guerra, prácticamente hablando no tuvo tiempo ni de hacer las indagaciones sobre estos acontecimientos, ni de imaginar todo ex nibilo. Puede ser que esto sea una hipótesis tentadora - que Vera escribiera los capítulos pares, pero a base de pura fantasía en el esfuerzo de imaginar lo que tuvo que haber pasado, dado el mito o el resultado de lo que sí pasó sin que él lo pudieta haber presenciado. Pero dado el sentido de la obra y, como se va a señalar a continuación, la importancia central de los capítulos pares, yo no puedo creer que así sea el asunto. El rol central de los capítulos que no escribió Vera es tan fuerte por presentarnos la visión de Roa Bastos de la fuer- 
za y el poder del pueblo paraguayo que el significado impresionante de su novela se esfumaría si uno tuviera que aceptar el que fueran simplemente el producto de la imaginación romántica de ese incapacitado moral. Por otra parte, quien siga insistiendo en que igual son de Vera, estará bajo la obligación para salvar la novela y rejustificarla, de suministrarnos una nueva interpretación de ella donde los capítulos imaginados por Vera en su fantasía, en contraste con los capítulos que no pretenden ser más que su memoria sentimental, cobren nuevo significado trascendente en el todo estructural de Hijo de bombre. ${ }^{7}$

Si lo susodicho no fuera suficiente como para probar que Vera no narra los capítulos pares, están algunas otras caracteristicas de la novela que nos apoyan en esta afirmación. Por ejemplo, si Gaspar Mora y Cristóbal Jara son las dos figuras cristológicas de la novela, una contemplativa y la otra activa, ¿por qué resultan tan distintos en su dimensión humana? Es decir, donde Jara es un hombre de carne y hueso ${ }^{8}$ en el sexto y octavo capítulos (donde realmente llegamos a conocerlo, y más en el octavo), de cierto heroismo callado -o mejor dicho, de un callado poder interior-- Mora, a quien no vemos directamente porque ya había muerto cuando el joven Vera recuerda a Macario en el primer capítulo, sale una figura a cartón, completamente romantizado y completamente mítico. Parte de la razón por este contraste de presentación está en que Mora, como dijimos, ya estaba muerto y convertido en mito, y parte está en que Vera recuerda lo que Macario relata en su chochez. Pero esto no es suficiente porque Vera, quien habla, pudo haber vuelto a Mora a una verosímil dimensión humana. Sin embargo, opta por aceptar la versión romántica - chocha- de Macario, quien es la inconsciente voz mítica del pueblo en su evocación de toda la pre-historia paraguaya. De esta manera, Mora sale romantizado porque ya es un mito y porque a Vera le gustan los mitos, especialmente los sentimentales que le tocan una raíz básica de su personalidad. De ahí sus cavilaciones en el primer capítulo sobre qué sïgnificará el Cristo, por qué había sido acogido tan espontáneamente por el pueblo, por qué se sigue celebrando el misterioso rito del Viernes Santo que nos ha valido a los itapeños el mote de fanáticos y de herejes" (p. 13).

${ }^{7}$ ¿Será que Vera, la persona, la máscara del autor, es incapaz de no ser sino sentimental cuando recuerda o evoca directamente (los capítulos impares), pero al mismo tiempo capaz de fuertes mitos del inconsciente colectivo cuando deja sus recuerdos egoístas al lado y se entrega completamente a la fantasía mística?

8 Se trazan las líneas importantes de esta personalidad de carne y hueso de Jara en mi estudio, "La importancia de Hijo de hombre de Roa Bastos en la literatura paraguaya", Duquesne Hispanic Review, 3 (1964), 95-106. 
También hay una gran variación estilística entre los capítulos pares y los impares. Estos, siendo el vivo recuerdo de Vera, son algo sentimentales, algo románticos, algo hiperbólicos, y la presencia de Vera como partícipe los reduce al mismo nivel de este romántico incapacitado y espiritualmente manco, según lo describe Rosa Monzón. Por contraste, el estilo de los capítulos pares es de una dimensión bíblica, donde el novelista trata de captar el sentido trascendental de las grandes empresas hu. manas, que por lo insignificantes y nimias que sean, hacen patente el poder del alma para sobrevenir, en esfuerzo monumental, su inmediata realidad degradante. El ruso, los padres de Jara, el mismo Jara son perfiles dotados de una fuerza de personalidad que Vera no habría podido comprender a fondo, ni mucho menos representar con el despersonalizado estilo bíblico de los capítulos pares. Aunque el asunto merece un estudio detallado antes de que podamos aceptarlo como comprobado, se sugiere que hay una diferencia significativa entre el estilo sentimental de Vera en los capítulos uno, tres, cinco, siete y nueve, y el estilo bíblicomítico de los capítulos dos, cuatro, seis y ocho. $\mathrm{Y}$ esta diferencia viene precisamente a apoyar la relativa importancia de éstos en comparación con aquéllos. Es en los capítulos pares donde el hombre es llevado a un nivel trascendental donde lo vemos en términos de las más radicales posibilidades de su ser: la lucha del médico entre un Bien y un Mal, igualmente poderosos los dos, la cual al final lo destruye; la afirmación inaudita y decisiva de los padres de Jara sobre una realidad que ya no pueden soportar porque va robándoles la dignidad de su ser, una dignidad que es reivindicada en su éxodo; la fraternidad de los hombres sutridos que permite la salvación de Jara, ya rodeado de la aureola de santo por la dignidad que ha heredado de sus padres; y finalmente, la tuerza del espíritu, encerrado dentro de su débil cuerpo mortificado, en Ilevar a cabo lo que ha aceptado como su misión, como responsabilidad para con sus hermanos. Contrastan con estos capítulos, los capítulos natrados por Vera. Excepto el primer capítulo que, por lo sentimental que sea, tiene mayor importancia por establecer el contexto de toda la nove1a, los otros cuatro son impresionantes por la falta de "grandeza" que resalta en los capítulos pares. Efectivamente, a estos (tres, cinco, siete y nueve), los he llamado transicionales con la idea de subrayar así lo antitéticos que son en comparación con dos, cuatro, seis y ocho. ${ }^{9}$

La función de este contrapunto de alternancia entre Vera y otro narrador no es difícil de encontrar: sirve precisamente para hacer resaltar la grandeza del ser humano -al menos los seres que giran en torno

9 Ver The Myth..., p. 72 . 
a Jara - y la bancarrota espiritual de tipos sentimentales y románticos como Vera, que no sólo no pueden comprender a los Jara, sino que también al final vienen a traicionarlos en la pobreza y vileza inconscientes de su carácter. Entonces, huelga preguntar quién es el segundo narrador. Aunque he sugerido que podría ser otra cara "objetiva" de Vera, lo dudo mucho. Pero no es inecesario que sea otro participante "histórico" de la novela: podemos decir simplemente que es el mismo Roa Bastos quien procede de esta forma para que el lector tenga el contraste tan significativo entre los dos puntos de vista que se entretejen en la novela. $O$ si se quiere una explicación más altisonante, podemos decir que es el mismo Cristo o cualquier Dios que pueda aceptar Roa, con el fin de que percibamos la diferencia entre el verdadero punto de vista mítico, y el punto de vista lastimosamente inadecuado de los Vera. Cualquiera que sea la conclusión sobre esta cuestión, en último plano no puede dejar de comprobar aún más la importancia de Hijo de bombre como uno de los más importantes -y mejor elaborados- documentos novelísticos de la literatura actual.

DAVID WILLIAM FoSTER

Arizona State University 